\title{
EFFECT OF ETHANOL-WATER COMPOSITION ON CLINDAMYCIN HYDROCHLORIDE PSEUDOPOLYMORPHISM
}

\author{
ILMA NUGRAHANI, SILVANA ANGGRAENI
}

Bandung Institute of Technology, Jl. Ganesha No.10, Kota Bandung, Jawa Barat 40132, Indonesia

Email: ilma_nugrahani@fa.itb.ac.id

Received: 16 Jul 2016 Revised and Accepted: 21 Sep 2016

\section{ABSTRACT}

Objective: Formation of clindamycin hydrochloride (clindamycin $\mathrm{HCl}$ ) in monohydrate-ethanolate from the recrystallization process with ethanolwater (5:2) has been reported a long time ago. However, the effect of ethanol-water compositions into pseudo-polymorphism formation and its stability of was not reported yet. This study aimed to investigate the effect of ethanol-water proportion on the formation of clindamycin HClmonohydrate and its ethanol solvate.

Methods: Clindamycin $\mathrm{HCl}$ was recrystallized with the various percentages of ethanol. The fresh and after storage for $24 \mathrm{~h}$ at humidity and room temperature $\left(25 \pm 2{ }^{\circ} \mathrm{C}, \mathrm{RH}: 70 \pm 1 \%\right)$ crystals were characterized by FTIR (Fourier transform infra-red), PXRD (powder x-ray diffractometer), and DTA (differential scanning calorimeter). The study of desolvation/dehydration then was observed with a polarization microscopy-plate heater.

Results: The results showed that monohydrate crystal was obtained from recrystallization in a concentration less than $50 \%$ ethanol in water. Next, the ethanolate was produced from the solvent of $>70 \%$ ethanol. Meanwhile, the $50-70 \%$ ethanol produced a hydrate-ethanolate, crystal, which has both hydrate and ethanol in its lattice. This hydrate-ethanolates was unstable, even in ambient temperature.

Conclusion: Concentration of ethanol in water as the solvent will determine the clindamycin HCl pseudo polymorphism, which will back to its original crystal form by the time of storage.

Keywords: Clindamycin $\mathrm{HCl}$, Hydrate, Ethanolate, Stability

(C) 2016 The Authors. Published by Innovare Academic Sciences Pvt Ltd. This is an open access article under the CC BY license (http://creativecommons.org/licenses/by/4. 0// DOI: http://dx.doi.org/10.22159/ijpps.2016v8i11.14132

\section{INTRODUCTION}

Solid active pharmaceutical compounds, including clindamycin $\mathrm{HCl}$, can arrange a pseudo-polymorphism, which is defined as the crystal involving water or other organic solvents in its lattice structure. If the solvent is water, the product is called a hydrate. Meanwhile if with an organic solvent, it is namely solvated. Then both are classified as sol vato morph [1, 2]. Tablet manufacturing, which usually involves solvent, drying and compression (mechanical energy) is likely affect the formation or loss of solvate [3]. Likewise, suspension dosage can affect the formation of hydrates. Solvate entrapment can cause changes in the physicochemical properties such as physical stability, compatibility, compressibility, flow rate, solubility, dissolution testing, and bioavailability of solid active pharmaceutical compounds [4, 5].

Clindamycin $\mathrm{HCl}$ is a lincomycin class antibiotic that works bacteriostatic, specifically against a wide range of gram-positive aerobic and anaerobic bacteria. Clindamycin is a lincosamide antibiotic that inhibits bacterial protein synthesis and is used for the treatment of anaerobic, streptococcal, and staphylococcal infections. The use of clindamycin is increasing in clinical practice due to its tolerability, efficacy and excellent tissue penetration various studies have shown the association between clindamycin and skin related problems. Clindamycin $\mathrm{HCl}$ is a white or nearly white crystalline powder, which is freely soluble in water and in ethanol. Clindamycin $\mathrm{HCl}$ can form hydrates and hydrate-solvates [6-8].

The state affects the activity of an antibiotic. Therefore, solids preparations, including hydrates and solvates have to be characterized, as well as their transformation and physical stability, as essential information for pre-formulation of ingredient-related activities. The three-dimensional structure of clindamycinhydrochloride-hydrate and its hydrate-ethanolate have been reported by Ravikumar and Sridhar [9] (fig. 1).

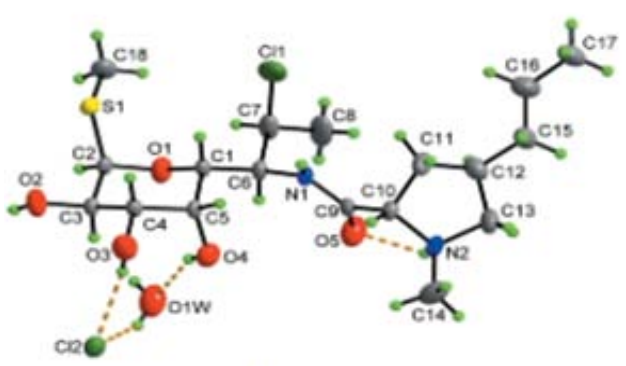

A

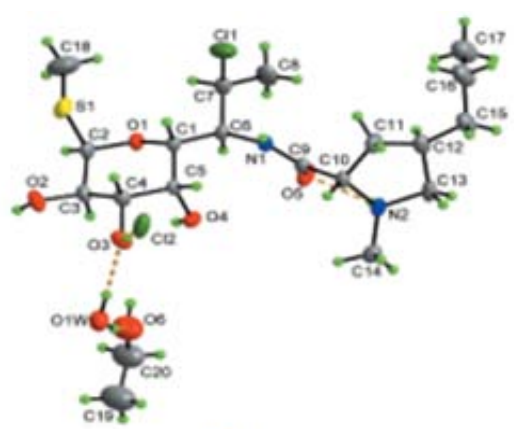

B

Fig. 1: Chemical structure of (A) clindamycin $\mathrm{HCl}$; three-dimensional structure of (B) clindamycin $\mathrm{HCl}$ monohydrate; (C) clindamycin $\mathrm{HCl}$ monohydrate-ethanolate 
Solid characterization widely studied to find more information, to support the dosage form formulation. As known, pseudopolymorphism will affect on drug dissolution and moreover, on bioavailability. This study requires a valid analysis used the instruments, such as: FTIR, DSC/DTA, PXRD, microscope (polarization, scanning electron), etc. Fortunately, some researchers have been reported the successful experiments on solid characterization. Furthermore, some methods of quantification of the amount of crystal changes/transformations also have been developed [1, 2, 9-16].

Nowadays, clindamycin $\mathrm{HCl}$ can be found at the market in tablet and liquid suspension. As a substance that has the possibility to change its crystal form, especially pseudo-polymorphism, the study of effect solvent should be done. The characterization and detection of clindamycin $\mathrm{HCl}$ pseudo-polymorphism have been reported $[9,10]$. However, so far, the effect of ethanol/water composition on clindamycin $\mathrm{HCl}$-hydrate and ethanolate formation still has not explained details yet. This stability also has not been investigated as to niclosamide solvate suspension [12]. This research aimed to investigate the effect of ethanol/water proportion on the kind of pseudo-polymorphism yielded from recrystallization. Afterward, this experiment also wanted to observe the stability of the pseudopolymorphism in the ambient temperature.

\section{MATERIALS AND METHODS}

\section{Materials}

Materials used in this experiment were: clindamycin $\mathrm{HCl}$ (batch no. P-003-ws12021501 from pharmaceutical industry PT Prydam, Indonesia), varied percentages of ethanol (Merck, Germany) in water (40, 50, 60, 70, 80, 95\%), KBr crystal (Merck, product No. 1049070500, Germany).

\section{Instruments}

Electronic scales milligrams (Mettler M3), FTIR (Jasco-4200 type A, Japan), PXRD (Philips-PW 18350 Xray Diffraction), DTA (TG8120, Seiko, Japan), polarization microscope (Olympus BX 50), magnetic stirrer (Thermolyne, USA), and other glassware used in the laboratory.

\section{Methods}

Clindamycin $\mathrm{HCl}$ was dissolved in ethanol with various percentages (95\%, 80\%, 70\%, 60\%, 50\%, and $40 \%$ in water) by magnetic stirring for $60 \mathrm{~min}$ at $40{ }^{\circ} \mathrm{C}$. Time by time these solutions were added with the solid until saturation. Then the solution is filtered and allowed to crystallize in the fume hood at room temperature. Crystals formed were investigated in their fresh states. Afterward after storage for $24 \mathrm{~h}$ at room temperature $\left(25 \pm 2{ }^{\circ} \mathrm{C}, \mathrm{RH}: 70 \pm 1 \%\right)$. These were characterized by a polarization microscopy to observe the habit and particle size. The next was characterization using FTIR, PXRD, and DTA. The last was an observation of the desolvation/dehydration process with the polarized microscopy-plate heater.

\section{Characterization with DTA}

Approximately 5-10 mg samples were kept in a special aluminum cup for the preparation of the DTA. Subsequently, the sample was heated under a stream of nitrogen gas with a heating rate $10^{\circ} \mathrm{C} / \mathrm{min}$, from 30 to $350^{\circ} \mathrm{C}$.

\section{Identification and characterization with FTIR}

Samples in powder form mixed crystals of potassium bromide that had previously been put into an oven at $100{ }^{\circ} \mathrm{C}$ with a weight ratio of $1: 100$, then were crushed until homogeneous with an agate mortar. Next, the dispersion was loaded into the mold of stainless steel discs measuring with the dimension $\pm 13 \mathrm{~mm}$, afterward compressed at a pressure of $\pm 7.5 \times 10-3 \mathrm{~mm}$ Hg using hydraulic presser. Finally, the disc was mounted on the holder spectra measured at wave number 4000 to $400 \mathrm{~cm}-1$ using FTIR spectroscopy Jasco- 4200 type A (Japan).

\section{Characterization by PXRD}

Analysis using PXRD done by a number of $200 \mathrm{mg}$ samples, which was prepared at the sample plate. The plate then tested by diffractometer with type: PW 1710 BASED; tube anode: Cu; voltage $40 \mathrm{kV}$, current of $30 \mathrm{~mA}, 0.2$ inches wide split. Data were collected at a scan speed of 0.8 seconds per step, with scanning distances at $2 \theta=5$ to $45^{\circ}$.

\section{Observation with polarization microscope and Kofler's hot stage}

A small amount of fresh and after storage crystals each was put on the objective glasses, then covered by cover glasses. Next, each sample preparation was put on Kofler's plate and heated. The detail of transformation was observed time by time thoroughly.

\section{RESULTS AND DISCUSSION}

\section{FTIR analysis}

Firstly, FTIR analysis was conducted to screen the changes of infrared spectra of the crystal compounds. The observation was focused especially to the hydrate or solvate included ethanolate area, which will be found on the wave number around $\pm 3500 \mathrm{~cm}^{-1}$ [10-12]. The presence of clindamycin HCl's water is indicated by a characteristic $\mathrm{OH}$ stretching bands in the in wave number $3400-3490 \mathrm{~cm}^{-1}$, meanwhile the $\mathrm{OH}$ of ethanolate found at about $(3500-3570) \mathrm{cm}^{-}$ 1[10]. Fig. 2 shows all the spectra yielded by FTIR measurement. Fig. 2A-a shows FTIR spectra of crystal, which yielded from $95 \%$ ethanol. Meanwhile fig. A-b the spectra after storage. Fig. 1B-a shows FTIR data, which is indicated that the crystals from ethanol above $70 \%$ formed hydrate-ethanolate. This was seen by the existence of a single hydrate and ethanolate peak. Next, the crystal from $50 \%$ ethanol showed only one peak (fig. 2C-a). Afterward, in fig. 1B-b, it is shown that this band(s) was lost after storage for $24 \mathrm{~h}$ at room temperature $\left(25 \pm 2{ }^{\circ} \mathrm{C}, \mathrm{RH}: 70 \pm 1 \%\right)$. Spectra FTIR of clindamycin $\mathrm{HCl}$ which were recrystallized loss its hydrate and ethanolate spectrums after storage for $24 \mathrm{~h}$ (fig. 2A-C, part b).
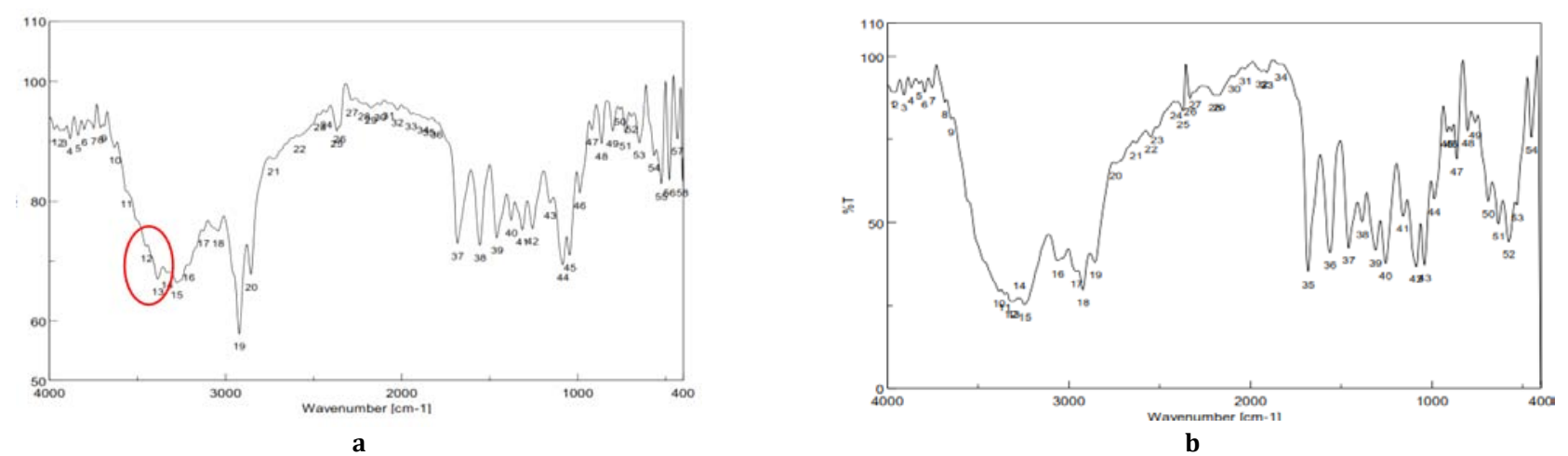

A. Spectrum of clindamycin $\mathrm{HCl}$ from ethanol 95\%: (a) fresh; (b) after $24 \mathrm{~h}$ of storage 


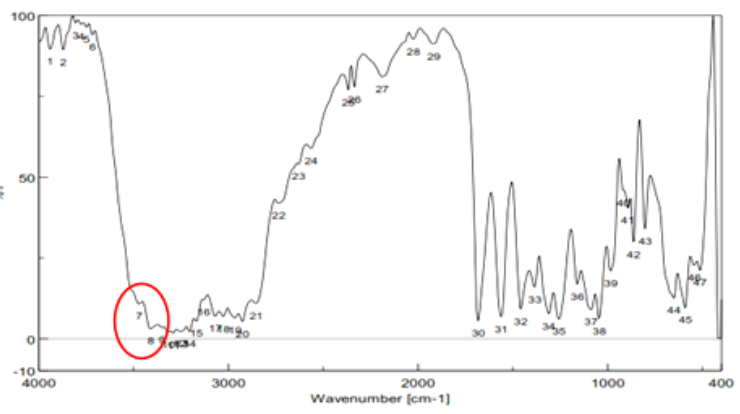

a

B. Spectrum of clindamycin $\mathrm{HCl}$ from ethanol $70 \%$

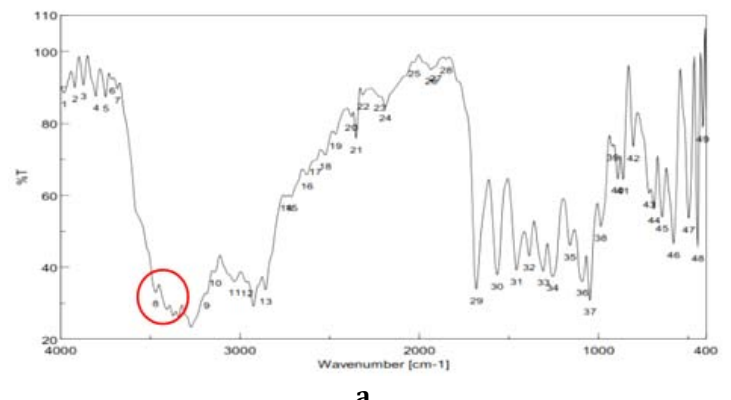

C. Spectrum of clindamycin $\mathrm{HCl}$ from ethanol 50 \%: (a) fresh; (b) after $24 \mathrm{~h}$ of storage

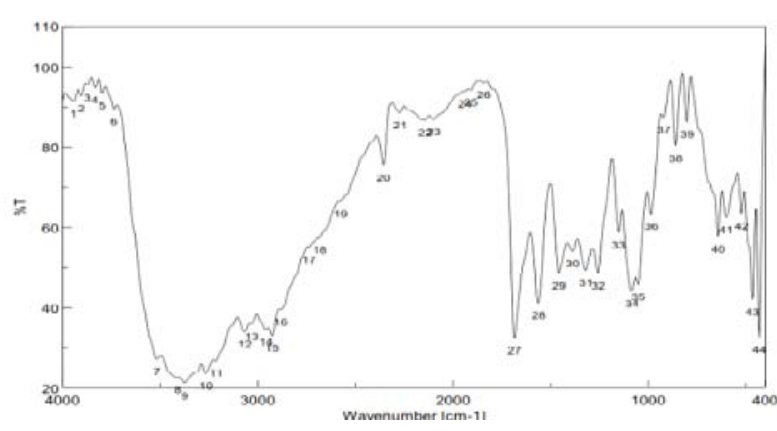

b

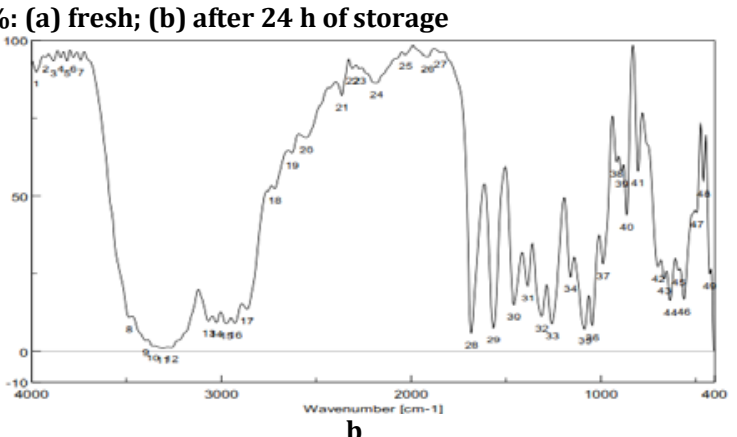

Fig. 2: FTIR spectra of clindamycin $\mathrm{HCl}$ crystal recrystallized with ethanol/water

Moreover, to make it clearer, the hydrate and ethanolate spectrums observed were listed in table 1 below;

Table 1: Stretching-OH in FTIR spectra of clindamycin HCl

\begin{tabular}{|c|c|c|c|c|}
\hline $\begin{array}{l}\text { Ethanol percentage of } \\
\text { solvent for recrystallize }\end{array}$ & Sample & $\begin{array}{l}\text {-0H solvate stretching at } \\
\text { wave number }\left(\mathrm{cm}^{-1}\right)\end{array}$ & $\begin{array}{l}\text { OH hydrate stretching } \\
\text { at wave number }\left(\mathrm{cm}^{-1}\right)\end{array}$ & Interpretation \\
\hline \multirow[t]{2}{*}{$95 \%$} & A & 3563.81 & 3451.96 & ethanolate and hydrate lost after \\
\hline & $\mathrm{B}$ & - & - & storage \\
\hline \multirow[t]{2}{*}{$80 \%$} & A & 3540.67 & 3432.67 & ethanolate lost, hydrate still remained \\
\hline & $\mathrm{B}$ & - & - & \\
\hline \multirow[t]{2}{*}{$70 \%$} & A & 3517.52 & 3409.53 & both hydrate and ethanolate lost after \\
\hline & $\mathrm{B}$ & - & - & storage \\
\hline \multirow[t]{3}{*}{$60 \%$} & A & 3544.52 & 3471.24 & both hydrate and ethanolate lost after \\
\hline & & & 3432.67 & storage. \\
\hline & $\mathrm{B}$ & - & - & \\
\hline \multirow[t]{2}{*}{$50 \%$} & $\mathrm{~A}$ & - & 3471.24 & no ethanolate, hydrate still remained \\
\hline & $\mathrm{B}$ & - & 3486.67 & after storage \\
\hline \multirow[t]{3}{*}{$40 \%$} & A & - & 3478.98 & no ethanolate, hydrate lost after \\
\hline & & & 3440.39 & storage \\
\hline & $\mathrm{B}$ & - & - & \\
\hline
\end{tabular}

Note: A: the sample before storage, B: the sample after storage in the humidity and room temperature $\left(25 \pm 2{ }^{\circ} \mathrm{C}, \mathrm{RH}: 70 \pm 1 \%\right)$.

After FTIR experiment, PXRD was used to observe the crystal changes. The diffractogram pattern will distinguish the crystal form produced from the series of recrystallization by ethanol/water. This analysis yielded the results as shown in fig. 3-5. Fig. 3 explains the change of diffractogram: fresh crystal from $95 \%$ ethanol/water, after it was stored, then both were compared to its origine crystal, as follows:

\section{PXRD analysis}

Next, crystallization was done with $70 \%$ ethanol/water, yielded diffractogram in fig. 4. This fig. compares the fresh crystal diffractogram with after storage and its origine.

The diffractograms in fig. 5 show the crystal yielded from $50 \%$ ethanol/water, the fresh and after storage, compare to its origine clindamycin $\mathrm{HCl}$.

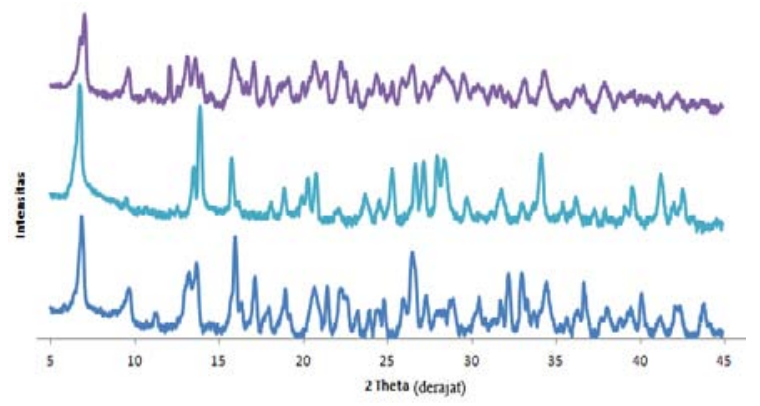

Fig. 3: Clindamycin $\mathrm{HCl}$ diffractogram of the recrystallized in ethanol 95\%: fresh crystal (top), after $24 \mathrm{~h}$ of storage (middle), and raw materials (bottom) 


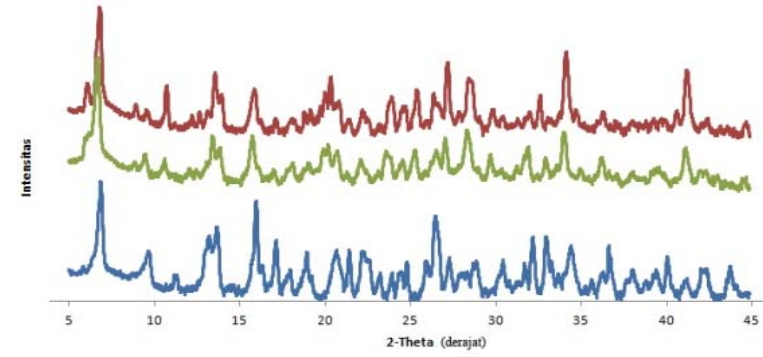

Fig. 4: Clindamycin $\mathrm{HCl}$ diffractogram of the recrystallized in ethanol 70\%: fresh crystal (top), after $24 \mathrm{~h}$ of storage (middle), and raw materials (bottom)

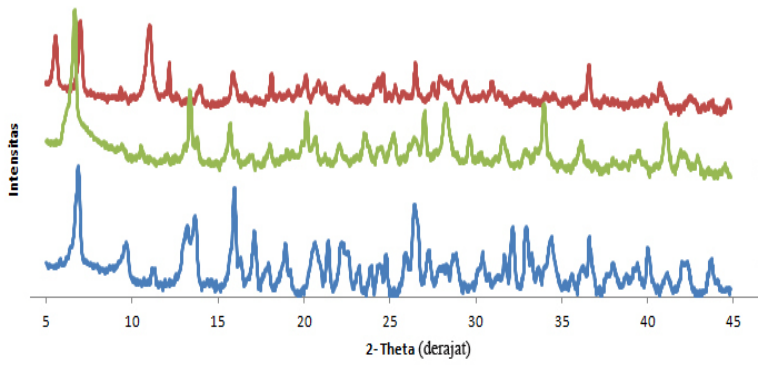

Fig. 5: Clindamycin $\mathrm{HCl}$ diffractogram from ethanol 50\%: fresh crystal (top), after $24 \mathrm{~h}$ of storage (middle), and raw materials (bottom)

\section{DTA analysis}

Differential thermal calorimetry is the analysis to know the internal energy of three-dimensional lattice crystal of the compound. A crystal should have a specific energy which determines its fix form. As known, all of the transformation need the change of energy. DTA was performed to analyze crystals produced from recrystallization with $40,50,60,70,80$, and $95 \%$ ethanol/water. The thermograms, curves yielded from this analysis, are shown in fig. 6.

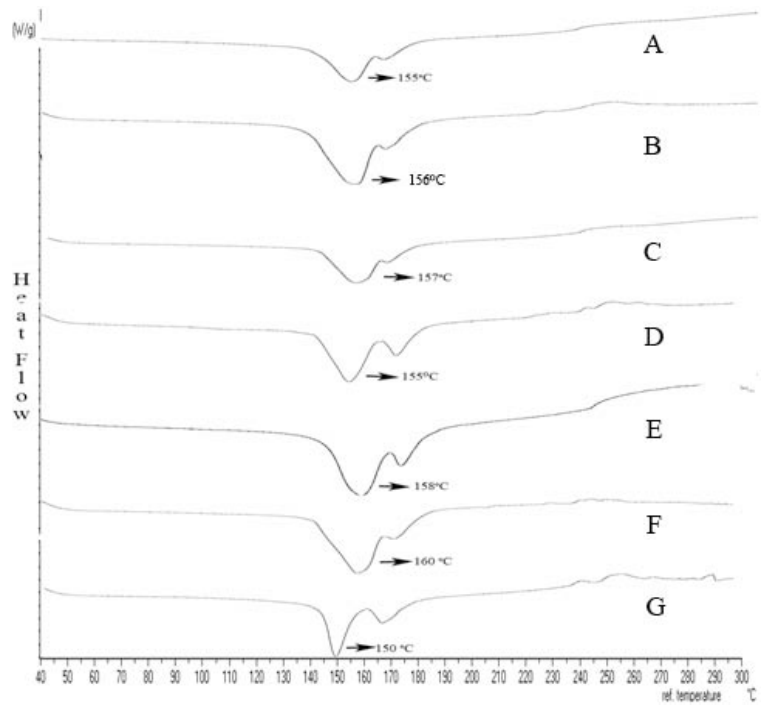

Fig. 6: Thermogram DTA clindamycin $\mathrm{HCl}$ crystal from a series concentration of ethanol: $40 \%$ (A), $50 \%$ (B), $60 \%$ (C), $70 \%$ (D), $80 \%$ (E), $95 \%$ (F), compared to the standard (G)

Afterward, DTA analysis also conducted on the crystals which had been stored at the ambient temperatures along $24 \mathrm{~h}$. The results were shown in fig. 7 as follows:

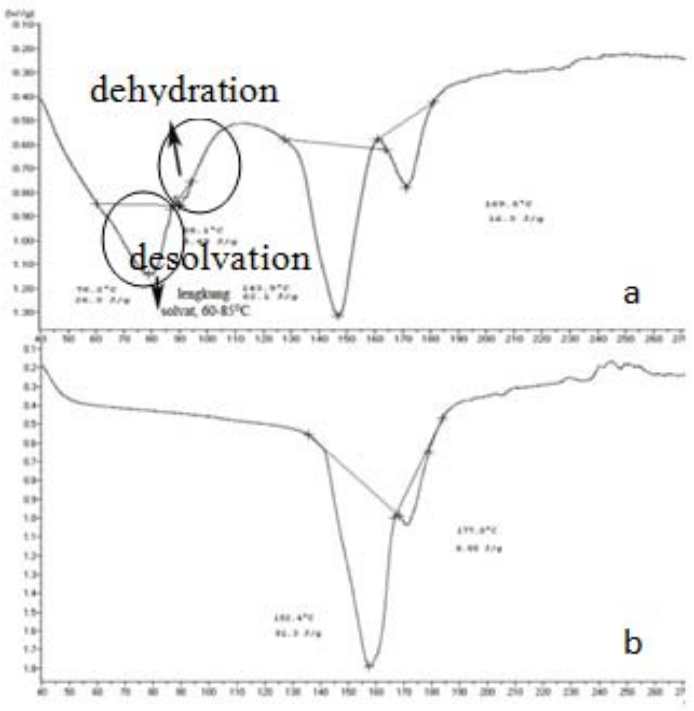

A

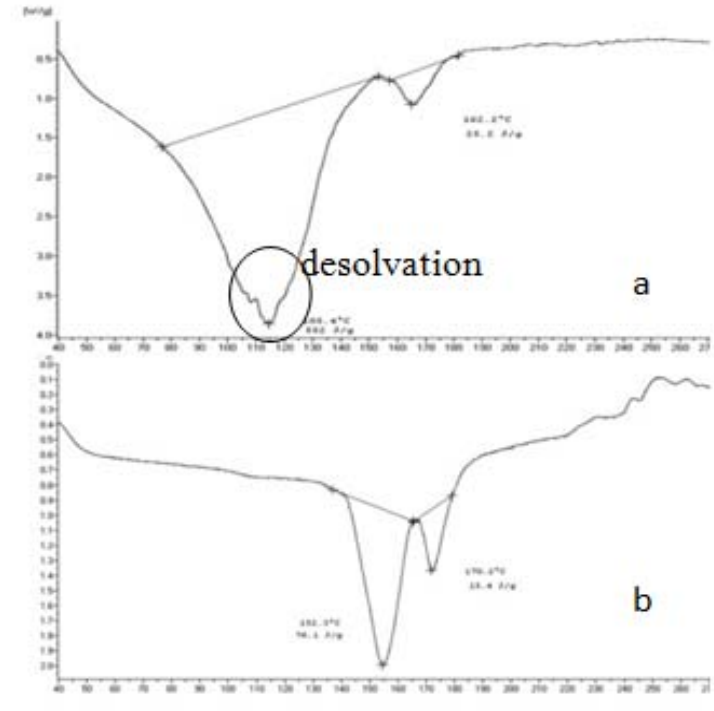

B

Fig. 7: Thermogram of crystals before and after the storage (at $25 \pm 2{ }^{\circ} \mathrm{C}, \mathrm{RH}: 70 \pm 1 \%$ ): A. crystal from $50 \%$ ethanol, fresh (a), after storage (b); B. crystal from ethanol 70\%, fresh (a), after storage (b)

Dehydration and desolvation observation by polarization microscope

Polarization microscope which completed with a heater plate (Koffler's hot stage) can show the dehydration and desolvation process. The release of water or ethanol from the crystals will be shown with the droplet around the heated substance. These processes were illustrated in fig. 8 below.

FTIR measurements of the crystals were performed as the first step of hydrate or ethanolate formation. Differ from surface water and solvent, which doesn't have the specific vibration peak, a 
hydrate/solvate should show a clear spectrum [10-12]. Fresh clindamycin $\mathrm{HCl}$ crystal from ethanol 70, 80, and 95\% showed infrared peaks at 3517-3563 $\mathrm{cm}^{-1}$ (fig. 2, table 1). It has been reported that ethanolate can be identified by a band at approximately 3500 $\mathrm{cm}^{-1}$, meanwhile the hydrate will show a peak at 3400 to $3490 \mathrm{~cm}^{-1}$ [11]. This indicated that the ethanol solvate crystals were formed in $>70 \%$ ethanol in water. Nevertheless, this band was lost after $24 \mathrm{~h}$ (table 1).
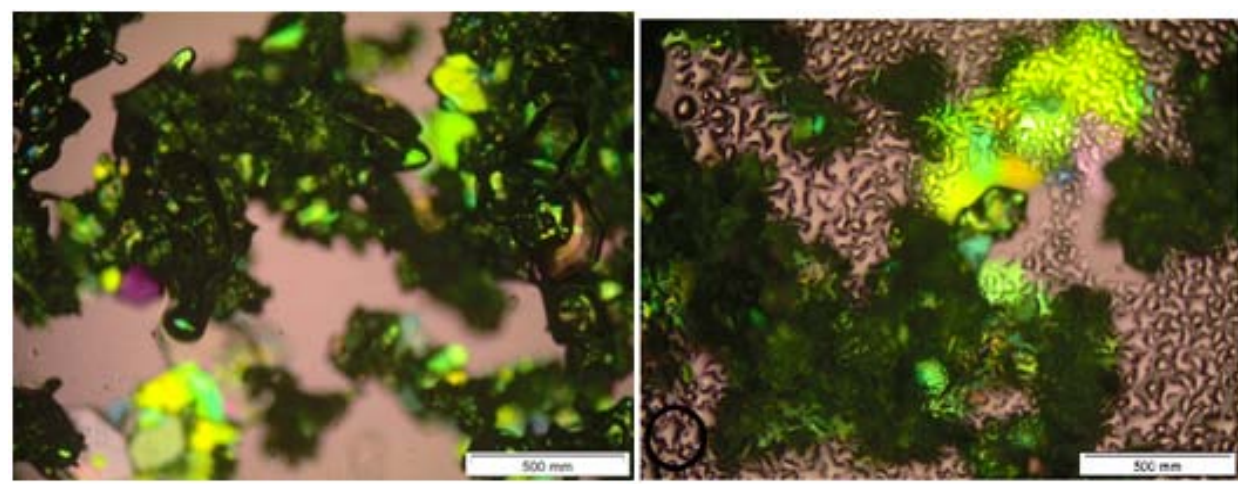

A
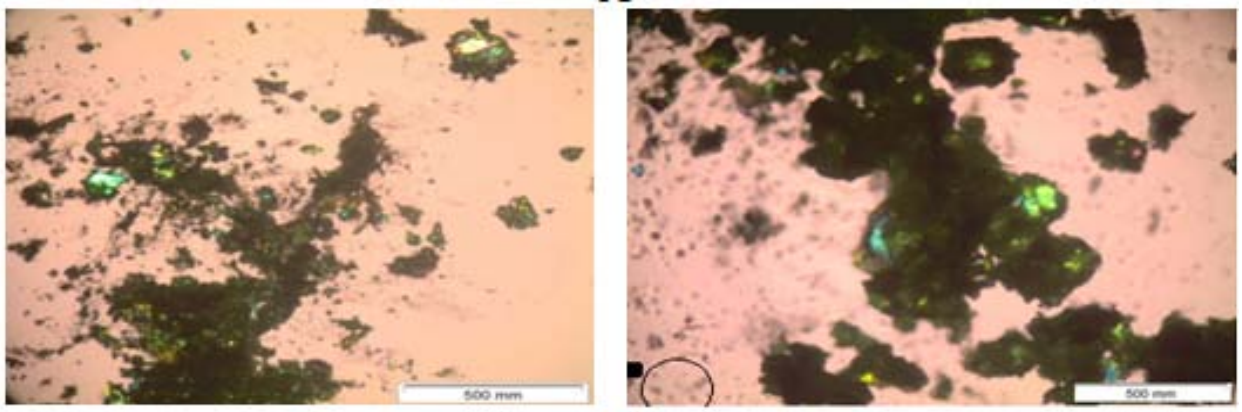

B

Fig. 8: The releasing of: ethanolate from clindamycin $\mathrm{HCl}$ hydrate-ethanolate at a temperature of $60-100{ }^{\circ} \mathrm{C}(\mathrm{A})$, hydrate from clindamycin $\mathrm{HCl}$ hydrate crystal at a temperature of $80-100{ }^{\circ} \mathrm{C}(\mathrm{B})$ (magnification 100-x)

In addition to the solvate peak around $3500 \mathrm{~cm}^{-1}$, a second peak is seen around $3400 \mathrm{~cm}^{-1}$. The recrystallized crystal from 40 and $50 \%$ ethanol showed only one peak. The presence of clindamycin HCl's crystal or hydrate water is indicated by a characteristic $\mathrm{OH}$ stretching bands in the in the wave number of $3400-3490 \mathrm{~cm}^{-1}$. Meanwhile, the $\mathrm{OH}$ of ethanolate was found at about $3500-3570 \mathrm{~cm}^{-}$ 1. This data was confirmed with Beckstead (1993) report [10]. With a single exception, this band(s) was also lost after storage for $24 \mathrm{~h}$ at room temperature $\left(25 \pm 2{ }^{\circ} \mathrm{C}, \mathrm{RH}: 70 \pm 1 \%\right)$ as shown in table 1 .

The crystals were stored for $24 \mathrm{~h}$, afterward were re-analyzed using FTIR measurement. The results showed that there were not solvate spectrums anymore at wave number $3500-3570 \mathrm{~cm}^{-1}$ region. Table 1 explains that the spectrum of fresh recrystallized clindamycin $\mathrm{HCl}$ (A) showed the difference compared to the storage crystal (B). This data indicated that along the storage, the releasing of ethanol/water molecules from the pseudo-polymorphism occurred. It predicted because of the low of energy interaction, which based by a small hydrogen bonding.

All the FTIR data indicated that the crystals from recrystallization with the percentage of ethanol above $70 \%$ had formed hydrateethanolate. There were seen the existence of a single hydrate and solvate peak (table 1). Then, percentage ethanol of less than $50 \%$ will form a hydrate, whereas $60 \%$ ethanol produced a mixture of hydrates and solvate-hydrates. This conclusion was based on the presence of single solvate peak and two hydrate peaks. Additionally, hydrate and hydrate-ethanolate lost its water and ethanol after stored for $24 \mathrm{~h}$, which was indicated by the disappearance of the hydrate and solvate spectra in the spectra.

For further analysis, it was used three kinds of samples: recrystallized with $50 \%, 70 \%$, and $95 \%$ ethanols. Recrystallized $70 \%$ and $95 \%$ was proven have arranged a hydrate-ethanolate, while recrystallized $50 \%$ produced the hydrate form. The further characterization was done by PXRD. This work was conducted to investigate the crystal structure changes during storage for $24 \mathrm{~h}$. The recrystallized from $95 \%$ ethanol (fig. 3-top) showed loss of solvate after the storage (fig. 3-middle), explained by the change from the pattern, which back to the original diffractogram, similar pattern with its raw material (fig. 3-bottom), especially at the important area at $2 \theta=5-25^{\circ}$.

Recrystallized clindamycin $\mathrm{HCl}$ in $70 \%$ ethanol (fig. 3-top) also shows solvate hydrate release after storage for $24 \mathrm{~h}$ (fig. 4-middle). This fig. Shows the diffractogram after storage was going to a similar pattern with raw material (fig. 4-bottom) with clear decreasing peak at $2 \theta=7^{\circ}$. Recrystallized clindamycin $\mathrm{HCl}$ in 50\% ethanol (fig. 5top) also released hydrate after $24 \mathrm{~h}$ of storage (fig. 5-middle). The diffractogram indicated, the hydrate released after storage $24 \mathrm{~h}$ showed by the similar pattern to the raw material (fig. 5-bottom).

Differential thermal analysis was used to observe the thermic character of clindamycin $\mathrm{HCl}$, which can represent its crystal lattice energy before and after storage. Change of crystal structure will be detected by the change of its pattern resulted. This measurement was done to the crystal yielded from $40-95 \%$ ethanol to confirm the types of pseudo polymorphism. Fig. 5 A-G show thermogram of fresh clindamycin $\mathrm{HCl}$ crystal from the series concentration of ethanol: $40 \%$ (A), 50\% (B), 60\% (C), 70\% (D), 80\% (E), 95\% (F), compared to the standard $(\mathrm{G})$. This fig. explain the existence of two new curves at a temperature of $60-100{ }^{\circ} \mathrm{C}$. This point of curves indicated as solvates and crystalline water released temperatures, however, the hydrate solvate and hydrate peaks stacked because of the release concurrently. From thermogram data, it has shown that all of the crystal arranged of pseudo polymorphism.

Furthermore, the diffractogram after storage along $24 \mathrm{~h}$ was shown in fig. 7. There was the peak, which marks the solvate hydrate has been lost. At the thermogram of fresh clindamycin $\mathrm{HCl}$ from ethanol, $50 \%$ is 
shown an endothermic curve at temperature $105-125^{\circ} \mathrm{C}$ (fig. $7 \mathrm{~A}-\mathrm{a}$ ). This curve is indicated the hydrate. Meanwhile in the thermogram of crystal after storage for $24 \mathrm{~h}$, there is no endothermic curve that marks the hydrate is no longer there (fig. 7A-b). It showed that the clindamycin $\mathrm{HCl}$ from ethanol $50 \%$ experienced dehydration after storage for $24 \mathrm{~h}$ at room temperature.

Thermograms in fig. 7B indicated there are not the hydrate and solvate from ethanol $70 \%$, both the fresh (7B-a) and after the storage (7B-b). The losing of solvate or hydrate curves indicates the instability of both ethanolate and hydrate form of clindamycin $\mathrm{HCl}$. The unstable pseudo polymorphism phenomenon has also been reported by Villiers and Mahlatji (2004). The research explains the physical instabilities of niclosamide solvates, which are formed at different carrier suspension [12].

The next analysis was performed to see the hydrate/solvate release from clindamycin recrystallized by $70 \%$ ethanol using a polarizing microscope with a heating plate. By heating under a polarized microscope, the loss of solvate/hydrate shown by the bubbles released from clindamycin $\mathrm{HCl}$ crystal. The result showed, clindamycin $\mathrm{HCl}$ from ethanol $70 \%$ had dehydration and desolvation starting from a temperature of $60-100{ }^{\circ} \mathrm{C}$. It was signed with the release of solvent bubbles from the crystal surface (fig. 8A). Similarly, it happened to clindamycin $\mathrm{HCl}$-ethanol $50 \%$, which showed the dehydration was starting from a temperature of $80^{\circ} \mathrm{C}$ to $100{ }^{\circ} \mathrm{C}$ in fig. $8 \mathrm{~B}$.

In general, the pseudo polymorphism phenomenon is the common cases for some drug substances, which will affect on drug dissolution, moreover, will influence the bioavailability. This phenomenon also can occur to clindamycin $\mathrm{HCl}$. Therefore, a good pre-formulary study should be conducted accurately in purposes to improve the best dosage formulation. From the crystal characterization study, it can be reached the planning for the optimal manufacturing process. This must be conducted to support all kinds of dosage form manufacturing since the very simple until the nano-drug formulations. The study can be conducted by severe instruments, which some have been explained before. These solid analyses instruments also have been reported used for the quantitative purpose besides qualitative characterization $[1,2,9-16]$.

\section{CONCLUSION}

Clindamycin $\mathrm{HCl}$ forms pseudo-polymorphism after its recrystallized in the mixtures of ethanol-water, which can be characterized with FTIR, DTA, PXRD, and polarization microscope. Percentage of ethanol in water will determine the kind of pseudo-polymorphism. The proportion of $>70 \%$ ethanol in water will form a monohydrateethanolate, meanwhile less than $50 \%$ of ethanol will produce only a hydrate, then between $50-70 \%$ of ethanol will compose the hydrateethanolate. However, these pseudo polymorphisms of clindamycin $\mathrm{HCl}$ were unstable after storage at $24 \mathrm{~h}$ in the ambient temperature $\left(25 \pm 2{ }^{\circ} \mathrm{C}, \mathrm{RH}: 70 \pm 1 \%\right)$.

\section{CONFLICT OF INTERESTS}

Declared none

\section{REFERENCES}

1. Storey AR, Ymen I. Solid state characterization of pharmaceutics. 1st ed. United Kingdom: John Wiley and Sons, LTD; 2011. p. 23.

2. Brittain HG. Polymorphism in pharmaceutical solids. $2^{\text {nd }}$ ed. New York: Informa Healthcare USA Inc; 2009. p. 233-6.

3. Vippagunta SR, Brittain HG, Grant DJW. Crystalline solids. Adv Drug Delivery Rev 2001;48:3-26.

4. Babra RS, Christopher PP, Adivaraha J, Adam JM, Nair RH. General principles of solid pharmaceutical polymorphs: a supramolecular perpective. Adv Drug Delivery Rev 2004;56:241-74.

5. Thompson C. investigating the fundamentals of drug crystal growth using atomic force microscopy. Thesis Magister, The University of Nottingham, England; 2003. p. 18, 27.

6. Thanusubramanian $\mathrm{H}$, Chogtu B, Magazine R. Adverse reaction due to clindamycin. Asian J Pharm Clin Res 2016;9:8-9.

7. Lund W. The pharmaceutical codex. $12^{\text {th }}$ ed. The Pharmaceutical Press: London; 1994. p. 41-43, 808-11.

8. Sweetman SC. Martindale: the complete drug reference. $36^{\text {th }}$ ed. London: Pharmaceutical Press; 2009. p. 251-3.

9. Ravikumar K, Sridhar B. Clindamycin hydrochloride and its ethanol solvate. Acta Crystallogr Sect C: Struct Chem 2010; 66:97-100.

10. Beckstead HD, Neville GA, Shurvell HF. Differentiation of solvated spirolactone samples by FT-Raman and FT-IR diffuse reflectance spectroscopy. Fresenius's J Anal Chem 1993; 11:727-32.

11. Nugrahani I, Ibrahim S, Mauludin R, Almira M. Hydrate transformation study of fluoroquinolone antibiotics using Fourier transform infrared spectroscopy (FTIR). Int J Pram Pharm 2015;7:246-52.

12. Villers MM, Mahlatji MD. The physical transformation of niclosamide solvate in pharmaceutical suspensions determined by DSC and TG analysist. Pharmazie 2004;59:534-40.

13. Junyavraperst VB, Morakul B. Nanocrystals for enhancement of oral bioavailability of poorly water-soluble drugs. Asian J Pharm Sci 2015;10:13-23.

14. Keshwani B, Jaimini M, Sharma D. Spherical crystallisation: a revolution in the field of particle engineering. Int J Curr Pharm Res 2015;7:19-25.

15. Dixit M. Preparation and characterization of spray dried microparticle and chilled spray dried particle of ketoprofen by spray drying method. Asian J Pharm Clin Res 2011;4:138-42.

16. Nugrahani I, Pertiwi EA, Putra OD. Theophylline-na-saccharine single crystal isolation for its structure determination. Int J Pharm Pharm 2015;7:15-24.

\section{How to cite this article}

- Ilma Nugrahani, Silvana Anggraeni. Effect of ethanol-WAter composition on clindamycin hydrochloride pseudo polymorphism. Int J Pharm Pharm Sci 2016;8(11):269-274. 